\title{
Monitoring the Wear of the Refractory Lining in the Blast-Furnace Hearth
}

\author{
A. N. Dmitriev ${ }^{a, c}$, Yu. A. Chesnokov ${ }^{a}$, K. Chen $^{b}$, O. Yu. Ivanov ${ }^{c}$, and M. O. Zolotykh ${ }^{a, c}$ \\ ${ }^{a}$ Institute of Metallurgy, Ural Branch, Russian Academy of Sciences, Yekaterinburg, Russia \\ ${ }^{b}$ Beijing Liberty International Engineering Technology Co., China \\ ${ }^{c}$ Yeltsin Ural Federal University, Yekaterinburg, Russia
}

\begin{abstract}
The Razgar Gorna computer program is developed for calculating two-dimensional temperature fields in any vertical and horizontal cross section of the blast-furnace hearth. In the calculations, the heatconduction equations are solved by means of readings from many temperature sensors (up to 1000, depending on the volume) installed within the furnace lining between the refractory modules. Continuous temperature monitoring at each point permits the determination of the remaining lining thickness and prediction of the onset of lining wear, as necessary. A mathematical model is employed in continuous temperature monitoring of the lining. The database of the Razgar Gorna program relies on the collection, analysis, and transmission of information from the temperature or heat-flux sensors. The program is in use at blast furnaces in Chinese steelworks at Jinan (two furnaces), Jiyuan, and Liuzhou.
\end{abstract}

Keywords: monitoring system, mathematical simulation, blast furnace, refractory lining, lining wear

DOI: $10.3103 /$ S0967091213110041

A blast furnace is a metallurgical system of shaft type. Its internal working space is bounded by a refractory lining, which is intended to protect the furnace's metal structures from high temperatures and to maintain the initial geometric configuration of the working space for a long time. Numerous factors break down the lining: impacts (when the charge is introduced in the furnace); abrasion (as the batch descends in the shaft); wear by the hot metal and slag; and the penetration of soot, zinc, and alkalis into the lining seams. The destructive effect is greatest in the lower part of the furnace: the lining of the well and the hearth. Therefore, appropriate measures are taken in the design of the refractory lining and the cooling systems in the well and the hearth, so as to minimize the need for major repairs and ensure reliable furnace operation for 15-20 years.

Considerable losses of production occur when large-capacity blast furnaces are shut down for lining repair, which may take 2-3 months. The factors responsible for wear and measures for its limitation were considered in [1]. The selection of the cooling system and the refractories and the furnace design are of primary importance here. The hot-metal fluxes associated with the hearth design and the quality of the coke employed also have some influence on hearth and hence furnace life. The influence of the productivity on furnace life was discussed in [1].

At present, Russian and non-Russian researchers are interested in the analysis of hearth operation and prediction of its wear, so as to prevent penetration of the hot metal through the lining, which would be catastrophic. The creation of adequate systems for such analysis and prediction calls for complex mathematical software, information regarding the latest achievements in blast-furnace technology, thermal calculations, and computer simulation.

At present, the lining thickness may be monitored by measuring the flow rate and temperature difference of the water entering and leaving the cooled furnace section and by means of thermosensors in the lower furnace lining. Other methods are based on ultrasound, radioactive isotopes, elastic shock waves, measurements of the resistance of electrofurnaces, and so on $[2-13]$.

The most promising approach is measurement of the lining temperature and corresponding calculation of the remaining lining thickness on the basis of mathematical models.

Existing diagnostic methods based on direct and indirect measurements involve solving nonsteady heat-conduction problems and the analysis of huge quantities of data-for example, in formulating a set of possible characteristic states of metallurgical systems or their components. The agreement between the models and the actual blast-furnace processes depends on the stability of the thermal and geometric characteristics on which the mathematical models of the refractory lining are based. 
The efficiency of existing automatic diagnostic systems for refractory linings may be increased by including a module detecting structural changes in the monitored signals in real time. As a rule, such changes indicate changes in state of the system being monitored. It is expedient to use the corresponding information in predicting the dynamics of the signals. Continuous operation of such a module permits timely detection of significant discrepancies.

We assume a one-dimensional steady flux $Q$ at the well and hearth walls. It may be described by the familiar formula for the flux through a multilayer plane wall [14]

$$
Q=\frac{T_{\mathrm{in}}-T_{\mathrm{ex}}}{\frac{1}{k_{1}} \Delta S_{1}+\ldots+\frac{1}{k_{n}} \Delta S_{n}},
$$

where $T_{\text {in }}$ and $T_{\text {ex }}$ are the internal and external surface temperatures of the walls; $\Delta S_{1, \ldots, n}$ is the thickness of the wall layer; $k_{1, \ldots, n}$ is the thermal conductivity of the wall layer.

We now consider two possible approaches to calculating the remaining lining thickness for three layers (for example, the lateral wall of a furnace), with two thermosensors.

1. With growth of the slag coating (Fig. 1), when a new layer (thickness $\Delta S_{x}$ ) with thermal conductivity $k_{x}$ is formed, we write

$$
\begin{gathered}
\frac{T_{x}-T_{1}}{\frac{1}{k_{x}} \Delta S_{x}+\frac{1}{k_{1}} \Delta S_{1}+\frac{1}{k_{2}} \Delta S_{2}+\frac{1}{k_{3}} \Delta S_{3}} \\
=\frac{T_{x}-T_{2}}{\frac{1}{k_{x}} \Delta S_{x}+\frac{1}{k_{1}} \Delta S_{1}+\frac{1}{k_{2}} \Delta S_{2}+\frac{1}{k_{3}}\left(\Delta S_{3}+\Delta S_{4}\right)},
\end{gathered}
$$

where $\Delta S_{x}=r_{0}-r_{x}$ is the coating thickness; $\Delta S_{1}=r_{1}-r_{0}$ is the thickness of the third layer; $\Delta S_{2}=r_{2}-r_{1}$ is the thickness of the second layer; $\Delta S_{3}=r_{3}-r_{2}$ is the thickness of the first layer; $\Delta S_{4}=r_{4}-r_{3}$ is the thickness of the layer between the sensors; $T_{1}$ is the temperature at the first sensor; $T_{2}$ is the temperature at the second sensor; $T_{x}$ is the temperature at the coating boundary (specified as $1150^{\circ} \mathrm{C}$ ); $k_{1}, k_{2}, k_{3}$, and $k_{x}$ are the heattransfer coefficients of the corresponding layers.

Hence, we may write the formula for the boundary $S_{x}$ of the lining with coating formation

$$
S_{x}=r_{0}+\frac{k_{x}\left[\begin{array}{c}
T_{1}\left(r_{4}-r_{2}\right)+T_{2}\left(r_{2}-r_{3}\right) \\
+T_{x} k_{2}\left(r_{3}-r_{4}\right)-k_{3}\left(T_{1}-T_{2}\right) \\
\times\left(k_{1}\left(r_{1}-r_{2}\right)-k_{2}\left(r_{2}-r_{0}\right)\right)
\end{array}\right]}{k_{1} k_{2} k_{3}\left(T_{1}-T_{2}\right)} .
$$

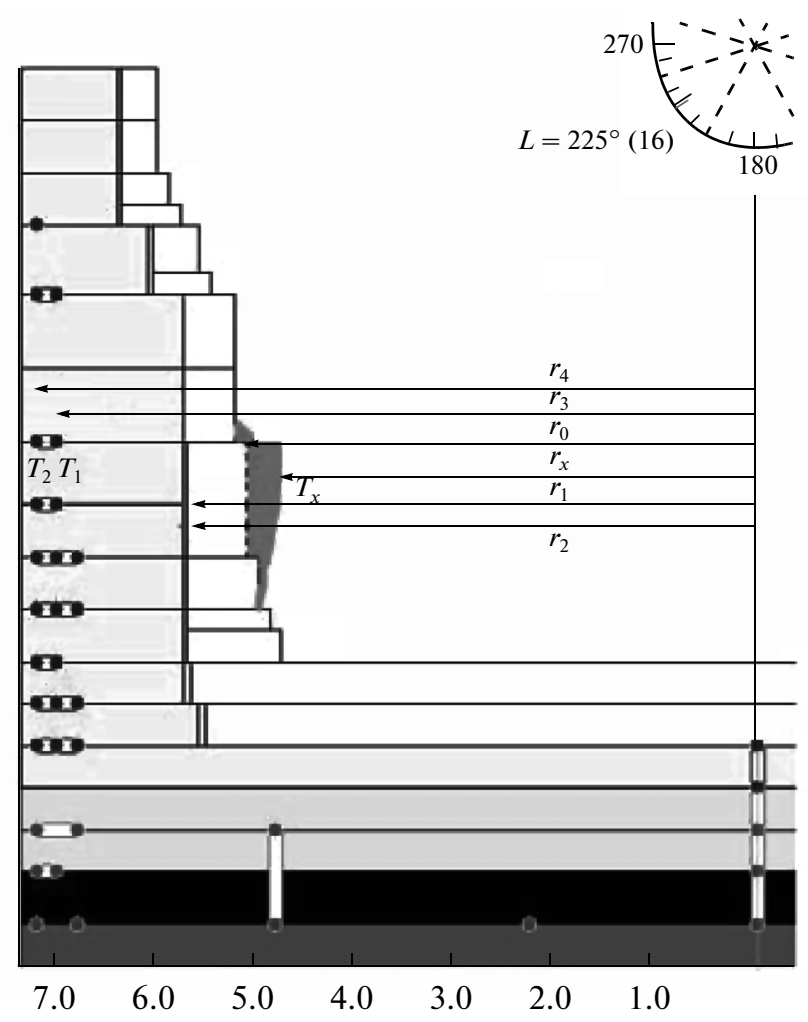

Fig. 1. Formulation of the problem with coating growth.

2. In the case of lining wear (Fig. 2), the layer thickness $\Delta S_{3}$ is reduced. Then the formula for the residual lining thickness $S_{x}$ takes the form

$$
S_{x}=S_{3}+\frac{k_{1} \Delta S_{2} \Delta S_{3}}{k_{3} \Delta S_{2}+k_{2} \Delta S_{3}} \frac{\left(T_{2}-T_{x}\right)}{\left(T_{1}-T_{2}\right)} .
$$

In this calculation, we need to verify that the calculated $S_{x}$ value satisfies the condition $\left|S_{x}-S_{3}\right|<0.001$, since the thickness of third layer may become critically small. Verification is based on the formula

$$
S_{x}=S_{2}+\frac{k_{1} \Delta S_{2}}{k_{2} \Delta S_{2}} \frac{T_{x}-T_{2}}{T_{2}-T_{1}}
$$

The same formula may be used when the third layer has completely burned away $\left(S_{x}<S_{3}\right)$. When readings from three or more sensors at the same level are obtained, the equations remain the same, but specified pair coefficients must be employed. In other words, the confidence level of the sensor readings must be taken into account. Analogous formulas may be obtained to calculate the thickness of the well lining; in that case, there are usually more than five layers.

From the given equations for a one-dimensional steady heat flux through a multilayer wall, if we calculate the boundary radius of the internal wall by linear interpolation (or any other method) when $T_{x}=$ $1150^{\circ} \mathrm{C}$ and the sensor readings $T_{1}$ and $T_{2}$ are known, 


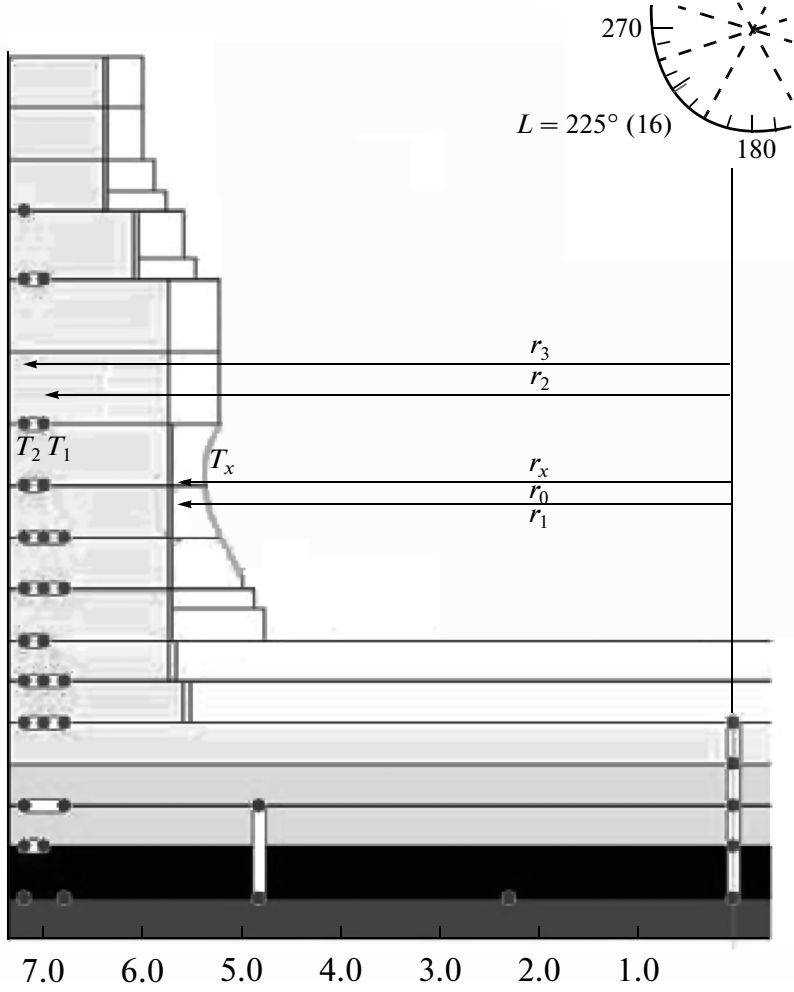

Fig. 2. Formulation of the problem with lining wear.

it is relatively simple to find the temperature distribution over the lining thickness in the region of the sensor positions. It is more difficult to establish the distribution of the temperature curves over the radius, between the groups of the sensors, in the well or the lateral walls of the blast furnace. The use of various numerical methods for difference schemes would require significant computer resources and machine time. Therefore, at this stage, we calculate the temperatures between the sensors (groups of sensors) by cubic-spline approximation [15]. We should also note here that the consistency of numerical methods becomes problematic at junctions where the grid switches from horizontal to vertical (or vice versa). The proposed approach offers speed (which is important in making timely decisions) but also adequate accuracy of the calculations.

The primary goals of the information system developed for monitoring the wear of the refractory lining in the blast-furnace hearth are to extend its working life and to prevent accidents in the blast furnace. Algorithms and programs have been developed for calculating the remaining lining thickness in the furnace hearth and the temperature distribution vertically and horizontally within the lining. On that basis, blast-furnace operation may be analyzed and controlled.

The program employs three windows: a window mapping the vertical cross section of the furnace; a

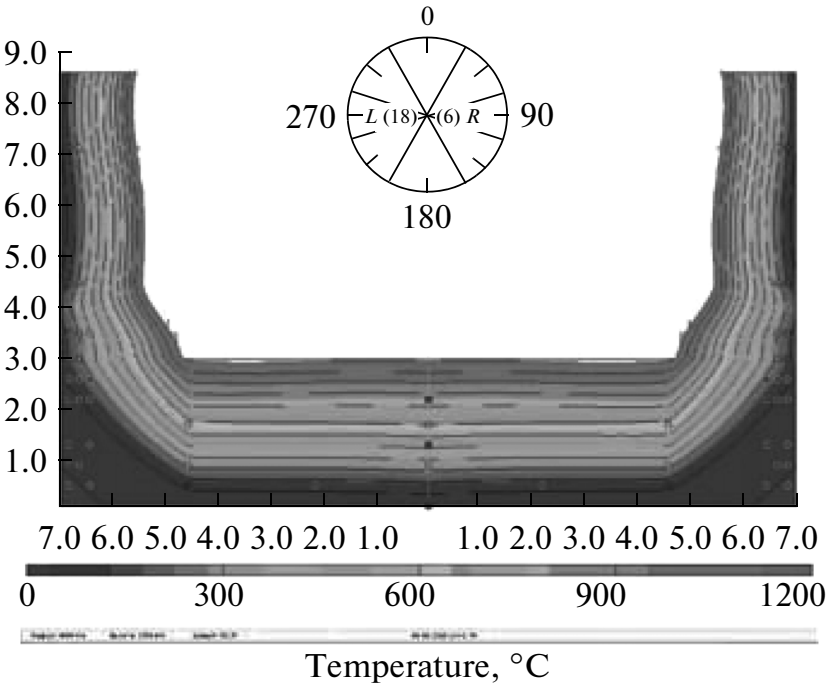

Fig. 3. Vertical cross section of blast furnace.

window mapping its horizontal cross section; and a window showing the parameter variation over time.

In the vertical cross section, most of the screen is devoted to two radial cross sections (Fig. 3). The drawing of the furnace predominates; its scale may be judged from the coordinate grid. The coordinates (height and radius) are expressed in $\mathrm{m}$. Above the radial cross sections, a sketch of the horizontal cross section is shown, with information regarding the positions of the left and right cross sections. Short bold lines at the circumference indicate these positions, and appropriate text is provided. For example, $L(18)$ means that the furnace cross section for sector 18 is shown on the left side, while (6) $R$ means that the right half shows the cross section for sector 6 . The same information may be provided in headline form: Vertical Cross Section of Blast Furnace with Azimuthal Angles of $270^{\circ}$ and $90^{\circ}$. Dashed lines show the boundaries of the sectors in containing the tap holes (four in Fig. 3), while long bold lines show their positions. Numerical values may be shown on the isotherms. Finally, the furnace may be colored in accordance with the local temperatures.

In Fig. 4, we show the horizontal cross section. As in the vertical case, we may observe the position of the thermocouples, the wear lines, isotherms, and coloration of the cross section in accordance with the local temperatures. Where necessary, numerical values may be shown on the isotherms. The inner section of the cross section is not colored, because this is a diagram of the hearth.

In Fig. 5, we show a screen displaying the variation in the remaining lining thickness. In Sensor Reading mode, we may track the change in the thermosensor readings over time. As an example, in Fig. 6, we show the variation in thermocouple readings within the 


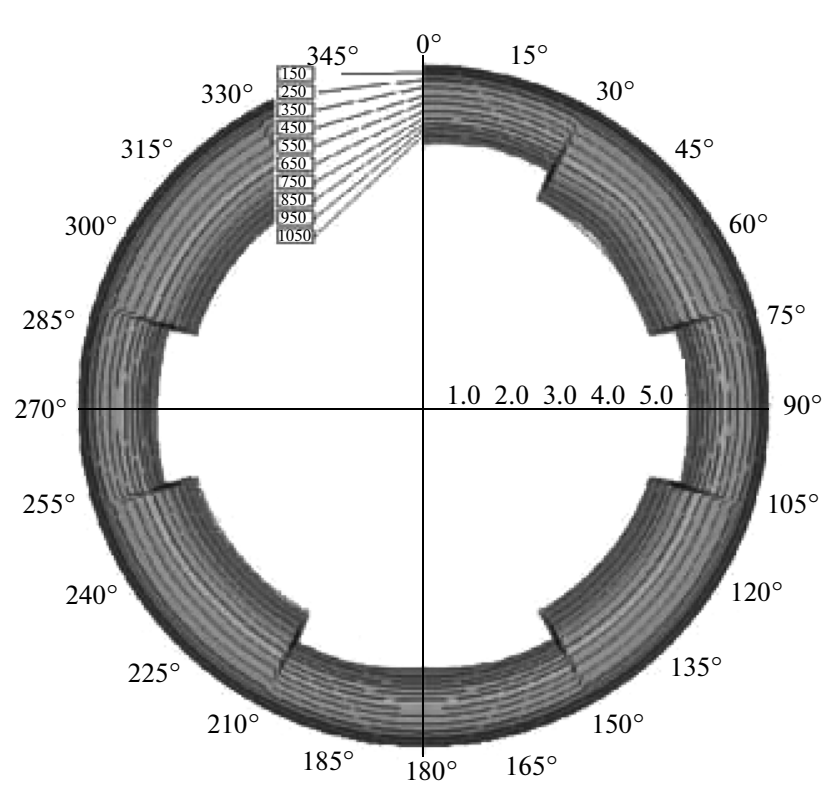

Temperature, ${ }^{\circ} \mathrm{C}$

Fig. 4. Horizontal cross section of blast furnace.

same horizontal cross section but in different groups, over the course of a week.

The Razgar Gorna computer program was installed at blast furnace 4 (volume $3200 \mathrm{~m}^{3}$ ) operated by Jinan Iron and Steel Co. (Jinan, China) at the end of 2010. Information is collected by 683 thermosensors. RS-232 controllers receive and send analog signals with a response frequency no less than $10 \mathrm{~Hz}$; the measuring precision is no less than $0.1 \%$.

Besides the Razgar Gorna computer program, KhA or NN thermal-conversion cables are used to measure the temperature in the hearth and well lining at specified points; gas-tight modules permit transfer of the cables outside the furnace and are soldered to the furnace housing; cross-connectors are placed around the furnace in accordance with the configuration of the gastight modules; and communication lines transfer the signals to the control panel. The monitors and other ancillary computer equipment employed are connected through a local network to the controllers of the primary computer in the control board.

The thermal-conversion cables are assumed to be standard devices for temperature measurements in gases, solids, or liquids, with two thermoelectrodes of KhA or NN type. The protective casing (diameter $3 \mathrm{~mm}$ ) is made of special alloy. The cables are produced in accordance with international standards and comply with State Standard GOST R 8.585-2001. They are shown in Fig. 7.

The gas-tight modules permit passage of the thermal-conversion cables outside the blast furnace. They consist of a metallic tube, within which the cables pass. The interior of the tube is sealed with special temper-

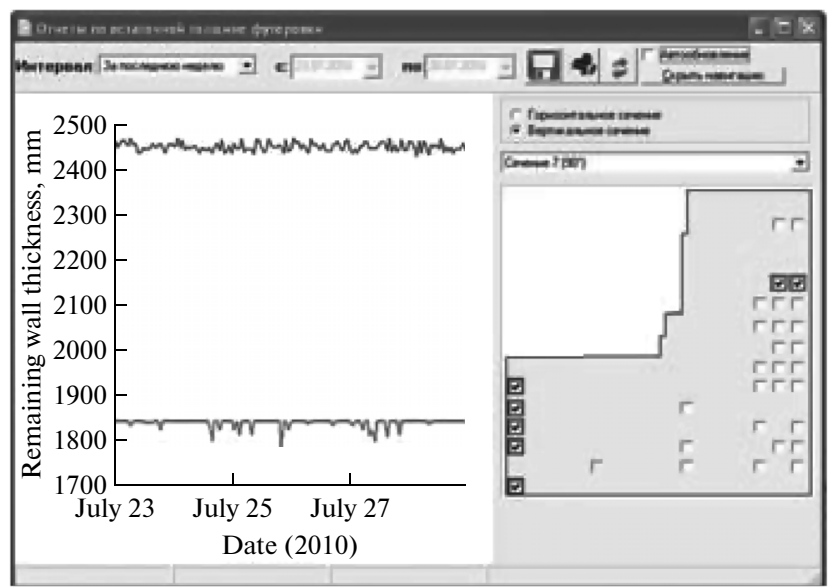

Fig. 5. Graphs of the remaining lining thickness.

ature-resistant material so as to ensure gas-tightness at $1000^{\circ} \mathrm{C}$ and $16 \mathrm{MPa}$. The modules are shown in Fig. 8 .

Prolonged operational experience shows that the system is highly reliable. However, the algorithm must be improved so as to take account of the complex profile in the lower part of the blast furnace. In particular, we want to construct a curve passing through points $A, B$, $C$, and $D$ in Fig. 9a. (These points are obtained by analysis of thermosensor readings.)

It is most expedient to use polar coordinates. In Fig. 9a, the origin of the polar coordinates is on the furnace axis, at the top of the hearth. The polar axis runs downward; the angle is measured clockwise.

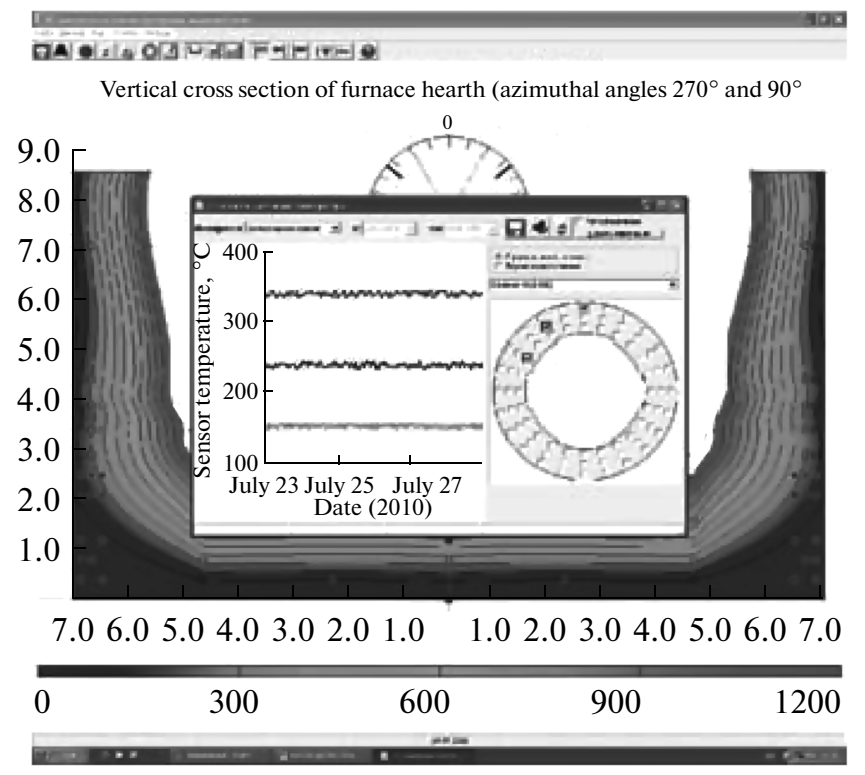

Temperature, ${ }^{\circ} \mathrm{C}$

Fig. 6. Operation in Sensor Reading mode. 


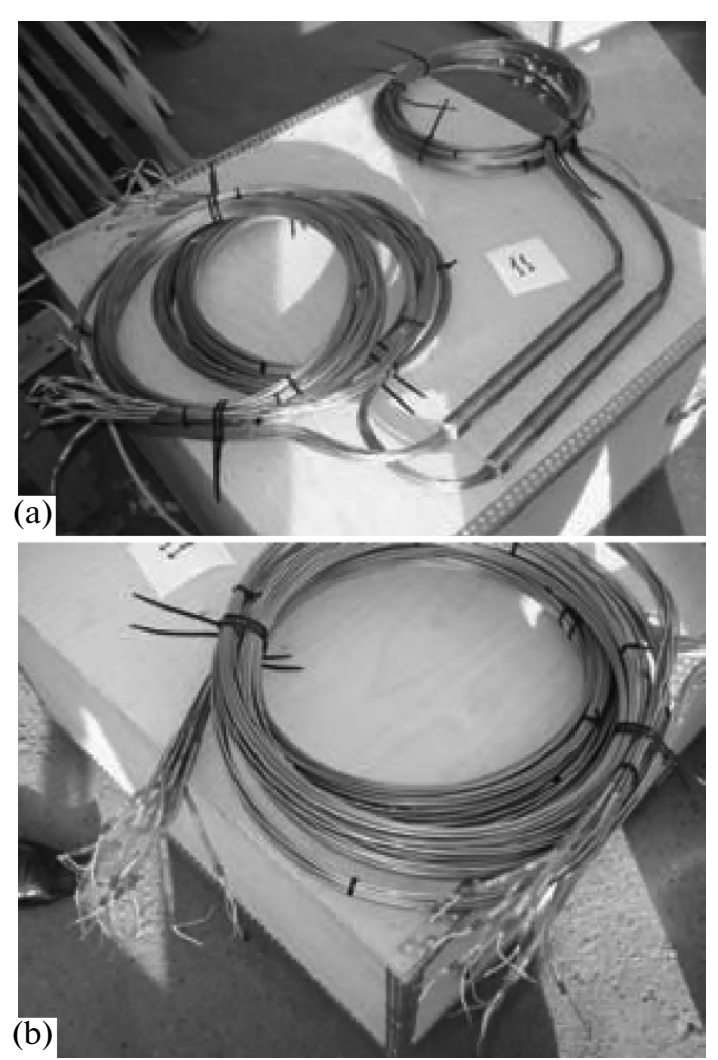

Fig. 7. Thermal-conversion cables.
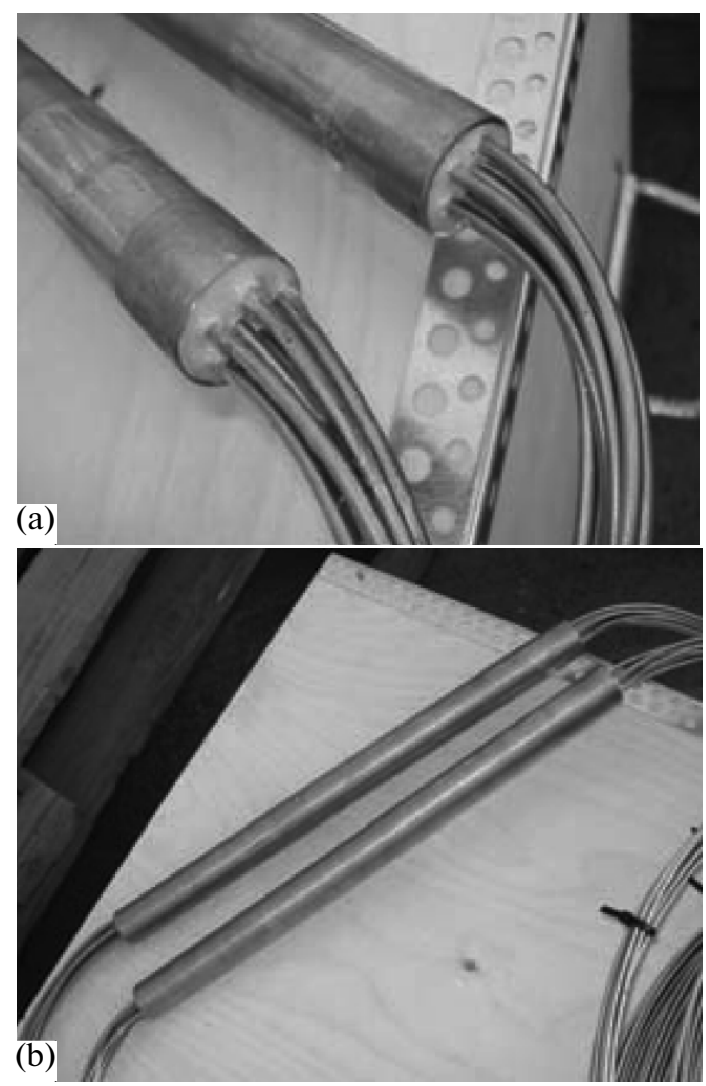

Fig. 8. Gas-tight modules. (a)

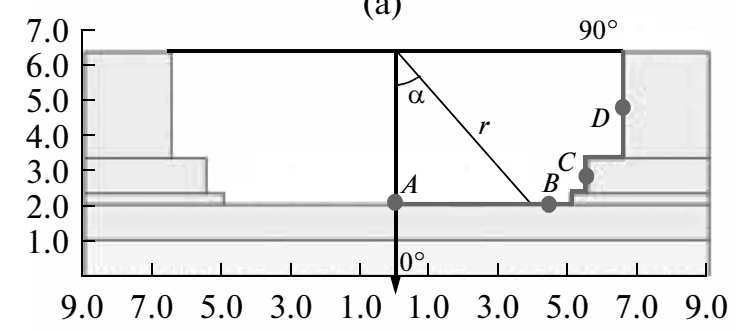

(b)

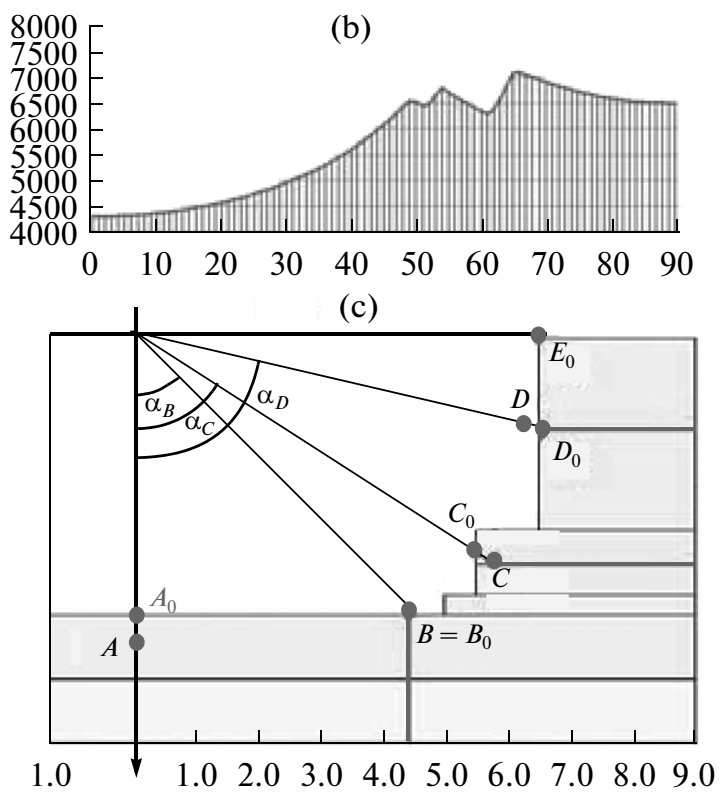

Fig. 9. Geometric relations (a), graph of $F(\alpha)$ (b), and lining thickness according to sensor readings (c).

Thus, the furnace profile may be represented by a function $r=F(\alpha)$ where $\alpha=0^{\circ}-90^{\circ}$ and $r$ is the radius. For the furnace geometry in Fig. 9a, $F(\alpha)$ takes the form in Fig. 9b. For the sake of clarity, we present highly simplified furnace geometry. However, the complexity of the profile has practically no influence on the interpolation method employed. As we see, $F(\alpha)$ has a smoothly varying section and a section with a large gradient. Correspondingly, its spectrum is relatively broad.

According to the Nyquist-Shannon theorem, this function must be established by selecting the distance between the readings $T_{\mathrm{d}}$ (the discretization interval) in the form $[16,17]$

$$
T_{\mathrm{d}}<1 / 2 f_{c},
$$

where $f_{c}$ is the upper frequency bound on the spectrum. This interval is not available in the diagnostic system considered here for the wear of a refractory blast-furnace lining. Therefore, to plot the curve, we require additional information-for example, the initial blast-furnace geometry (profile), which is known in advance. 


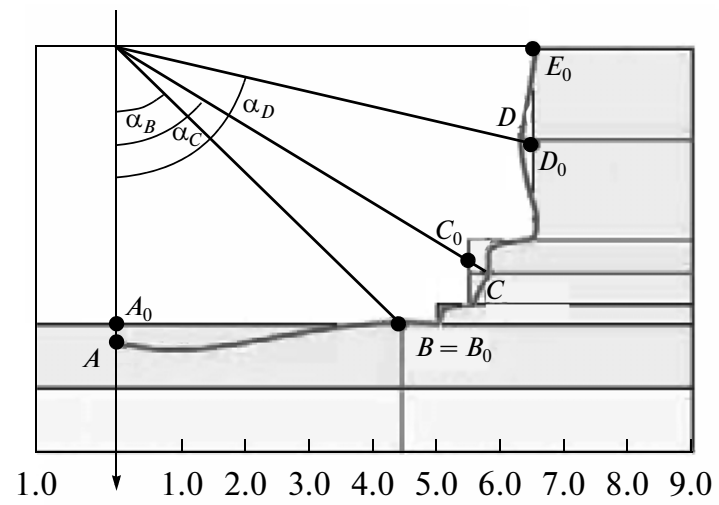

Fig. 10. Result of interpolating the furnace profile.

We now consider the interpolation method for the example in Fig. 9c. In furnace operation, the geometry changes (wear or coating application). Information regarding the current profile is provided by thermosensors in the lining. On the basis of temperature readings at the sensors, the remaining lining thickness in the hearth and well at specific points is determined. Points $A, B, C$, and $D$ correspond to the calculated lining thickness. Subscript 0 denotes the initial points of the function $F(\alpha)$ (the initial furnace profile) at the corresponding angular coordinate. To obtain the current profile, we need to determine $F^{\prime}(\alpha)$, by interpolation of the values at points $A-D$ on the basis of $F(\alpha)$.

Interpolation will be undertaken on individual segments. On segment $\alpha_{A}-\alpha_{B}$, the values of $F^{\prime}(\alpha)$ are mainly determined by the thermosensor readings at point $\alpha_{A}$ and $\alpha_{B}$. The influence of the other thermosensors is negligible, and therefore they will be ignored. To form the last segment of the function $F^{\prime}(\alpha)$, we introduce the point $E_{0}$ at the top of the hearth $\left(\alpha_{E}=90^{\circ}\right)$. The lining thickness at this point is always the same, since the probability of lining wear at that point is negligible. tors.

In interpolation, we must take account of two fac-

1. With slight wear (buildup), $F^{\prime}(\alpha)$ must maintain the initial furnace geometry.

2. With greater wear, the form of the cross section changes, on account of lining disintegration.

These two factors impose opposite requirements on the interpolation algorithm. To obtain a compromise, we need an adaptive interpolation procedure. An example is as follows

$$
\begin{gathered}
F^{\prime}(\alpha)=F_{1}^{\prime}(\alpha)|P-d(\alpha)| / P+F_{2}^{\prime}(\alpha) \\
\times(1-|P-d(\alpha)| / P) \text { when } d(\alpha)<P, \\
F^{\prime}(\alpha)=F_{2}^{\prime}(\alpha) \text { when } d(\alpha) \geq P .
\end{gathered}
$$

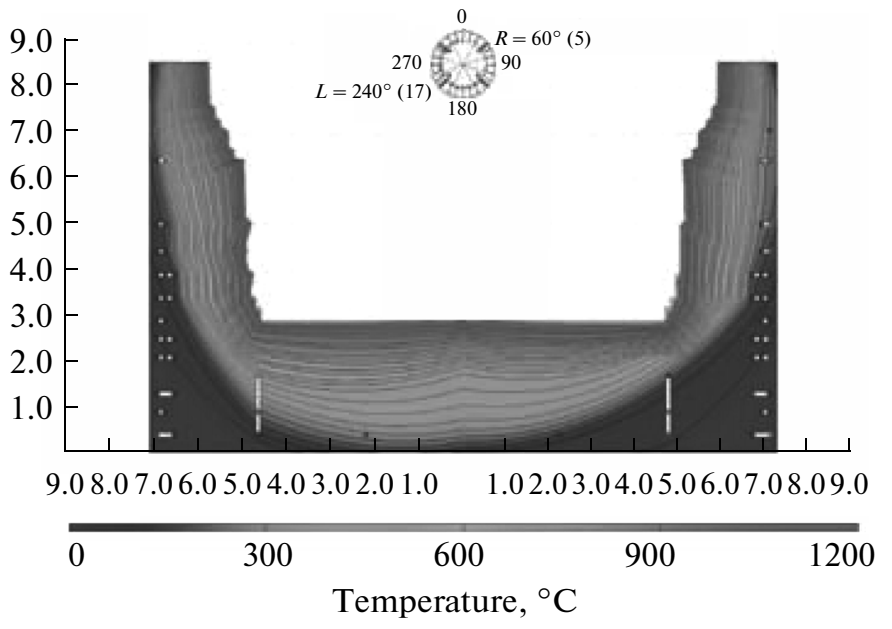

Fig. 11. Vertical cross section of the hearth in $3200-\mathrm{m}^{3}$ blast furnace 4 at Jinan Iron and Steel Co. for azimuthal angles of $240^{\circ}$ and $60^{\circ}$.

Here $d(\alpha)$ is the auxiliary function, which characterizes the deviation of the calculated value from the initial profile. For segment $\alpha_{A}-\alpha_{B}$

$$
\begin{gathered}
d(\alpha)=\left[A_{0}-A+\left(\left(B_{0}-B\right)\right.\right. \\
\left.\left.-\left(A_{0}-A\right)\right)\right] /\left[\left(\alpha_{B}-\alpha_{A}\right)\left(\alpha-\alpha_{A}\right)\right] .
\end{gathered}
$$

Also in Eq. (7), $P$ is the threshold value of $F^{\prime}(\alpha)$; $F_{2}^{\prime}(\alpha)$ is the interpolation function for large changes in furnace geometry. In the simplest case of linear interpolation

$$
F_{2}^{\prime}(\alpha)=A+(B-A) /\left(\alpha_{B}-\alpha_{A}\right)\left(\alpha-\alpha_{A}\right) .
$$

The interpolation of the other segments $\left(\alpha_{B}-\alpha_{C}\right.$, $\alpha_{C}-\alpha_{D}$, and $\alpha_{D}-\alpha_{E}$ ) is analogous. In Fig. 10, we show the result of interpolation for this example.

This method of interpolation is not intended to find local lining defects between the groups of temperature sensors. Therefore, the sensors must be placed at the most likely defect sites. It is very important to place backup sensors at the center of the furnace, since failure of the sensors at that location renders interpolation impossible.

In Fig. 11, we show the vertical cross section of the hearth in $3200-\mathrm{m}^{3}$ blast furnace 4 at Jinan Iron and Steel Co. (Jinan, China) for azimuthal angles of $240^{\circ}$ and $60^{\circ}$. The position of the thermocouples is evident in Fig. 11. Information regarding the wear at points without sensors may be obtained on the basis of the proposed algorithm, by taking account of the readings of several thermocouples in a row.

This system has also been installed in $1080-\mathrm{m}^{3}$ blast furnace 2 at Henan Jiyuan Iron and Steel Co. and in $2500-\mathrm{m}^{3}$ blast furnace 4 at Guangxi Liuzhou Iron and Steel (Liuzhou, China), with 212 and 383 thermocouples, respectively. 


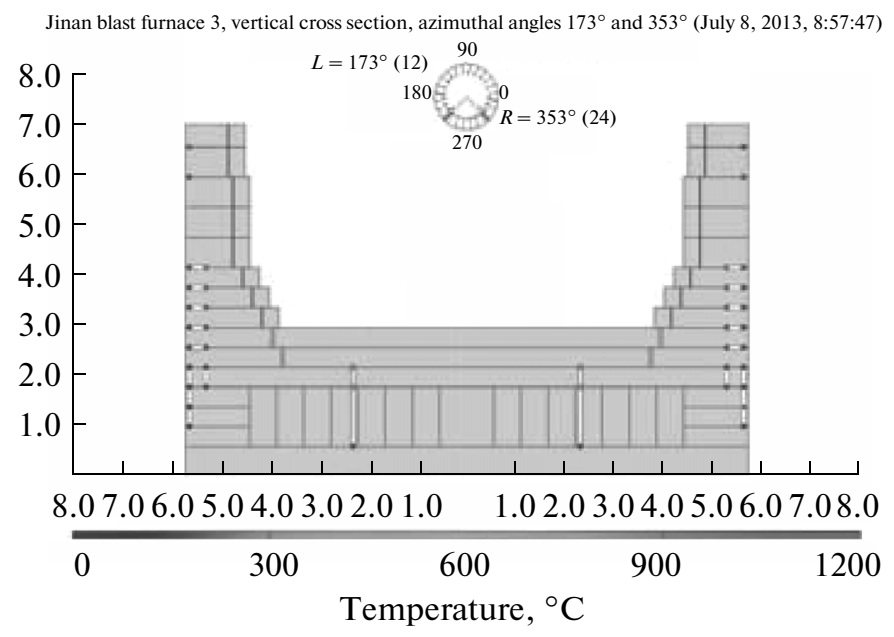

Fig. 12. Vertical cross section of the hearth in $1750-\mathrm{m}^{3}$ blast furnace 3 at Jinan Iron and Steel Co.

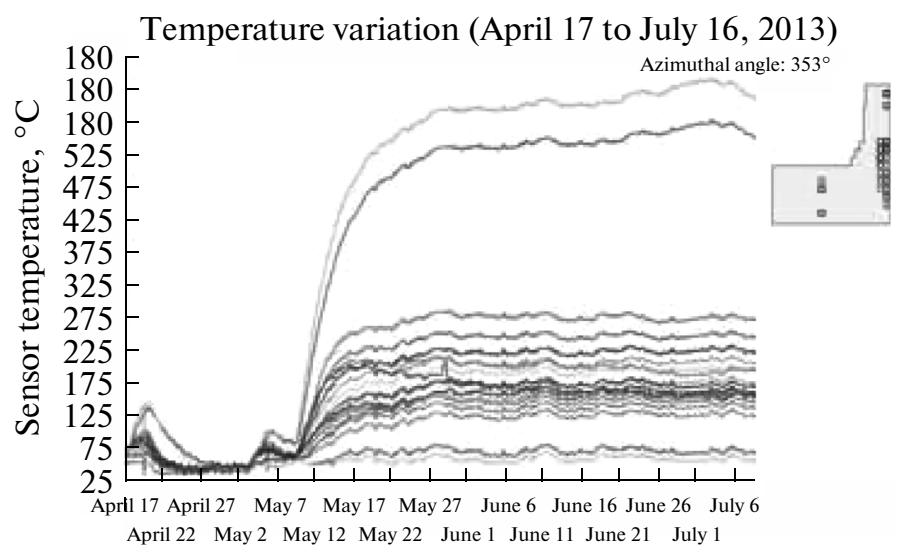

Date (2013)

Fig. 13. Temperature variation at the thermocouple locations in a vertical cross section of the hearth in $1750-\mathrm{m}^{3}$ blast furnace 3 at Jinan Iron and Steel Co.

In March 2013, during major repairs, the proposed system was also installed in $1750-\mathrm{m}^{3}$ blast furnace 3 at Jinan Iron and Steel Co., with 524 thermocouples (Fig. 12). This system was used to monitor the furnace as it was restarted, beginning on May 15, 2013. In Fig. 13, we show the temperature variation at the thermocouples for a single vertical cross section in the furnace hearth.

\section{CONCLUSIONS}

A new system for monitoring the lining wear in the blast-furnace hearth has been introduced at several steel plants in China. The system includes a program for calculating two-dimensional temperature fields in any vertical and horizontal cross section of the hearth lining on the basis of thermosensor readings.

\section{REFERENCES}

1. Kowalski, W., Luengen, H.B., and Stricker, K.P., Life of blast furnaces: developments at various companies, Chern. Met., 1999, no. 9, pp. 26-35.

2. Gavrilov, E.E., Ul'yanov, A.G., Kanaev, V.V., and Mozharenko, N.M., Diagnostics of the lining in the metal intake of a blast furnace in terms of thermal loads, Stal', 1987, no. 1, pp. 13-15.

3. Kudinov, A.G., Lysenko, E.E., and Kobal', A.V., Ispol'zovanie vtorichnykh energoresursov i okhlazhdenie agregatov chernoi metallurgii: temat. sb. nauch. tr. NPO Energostal' (Utilization of Secondary Energy Resources and Cooling of Iron- and Steel-Production Systems: Proceedings of NPO Energostal'), Moscow: Metallurgiya, 1991, pp. 11-13.

4. Kudinov, G.A., Krishtal', V.A., and Lysenko, E.E., Computer diagnostics of the refractory-lining wear in the blast-furnace hearth and well, Stal', 1997, no. 10, pp. 10-12. 
5. Vasil'ev, P.G., Levchenko, V.E., Alpaev, N.E., and Shul'ga, A.V., Diagnostics of the lining in the metal intake of a blast furnace in terms of thermal loads, Metallurg. Gornorud. Prom., 1992, no. 3, pp. 3-5.

6. Shvydkii, V.S., Lavrov, V.V., and Spirin, N.A., Mathematical model of the diagnostic system for blast-furnace linings, Nauchnye osnovy konstruirovaniya metallurgicheskikh pechei. Mezhdunarodnaya konferentsiya (Design Principles for Metallurgical Furnaces: An International Conference), Dnepropetrovsk: Porogi, 1993, pp. 10-11.

7. Spirin, N.A., Fedulov, Yu.V., Novikov, V.S., et al., Diagnostics of the lining in a blast furnace in terms of temperature field, Stal', 1997, no. 10, pp. 13-16.

8. Serov, Yu.V., Makienko, V.G., Brazhko, V.N., et al., New information technologies in monitoring the blastfurnace hearth, Stal', 1997, no. 10, pp. 4-9.

9. Shul'te, M., Klima, R., Ringel, D., and Foss, M., Monitoring the wear in the blast-furnace hearth by means of heat-flux sensors, Chern. Met., 1998, no. 4, pp. 17-22.

10. Makienko, V.G. and Dumbur, R.S., Diagnostics of the blast-furnace lining: Diagnostics of the lining in the metal reservoir and well, http://chermet.in.ua/index.php? view $=$ article $\&$ catid $=31 \% 3$ Ascience $\& i d=52 \% 3$ Astatraz.

11. Li Yu, Monitoring Blast-Furnace Erosion: Principles, Analytical Methods, and Engineering Applications (Rus- sian translation), Shenyan, China: North-Western University, 2009.

12. Koshelev, A.E., Krivolapova, L.I., and Kravtsova, O.A., Diagnostic subsystem for the components of metallurgical equipment within the enterprise's automatic control system, Dokl. TUSUR, 2008, no. 2(18), part 2, pp. 110-116.

13. Hong-bo, Z., Shou-feng, H., and Shu-sen, C., Study on the early warning mechanism for the security of blast furnace hearths, Intern. J. Min., Metall., Mater., 2013, vol. 20, no. 4, pp. 345-353.

14. Telegin, A.S., Shvydkin, A.S., and Yaroshenko, Yu.G., Teplomassoperenos (Heat and Mass Transfer), Moscow: Metallurgiya, 1995.

15. Zav'yalov, Yu.S., Kvasov, B.I., and Miroshnichenko, V.L., Metody splain-funktsii (Spline-Function Methods), Moscow: Nauka, 1980.

16. Nyquist, H., Certain topics in telegraph transmission theory, Trans. AIEE, 1928, vol. 47, pp. 617-644.

17. Basarab, M.A., Zelkin, E.G., Kravchenko, V.F., and Yakovlev, V.P., Tsifrovaya obrabotka signalov na osnove teoremy Uittekera-Kotel'nikova-Shennona (Digital Signal Analysis on the Basis of the Whittaker-Shannon Theorem), Moscow: Radiotekhnika, 2004.

Translated by Bernard Gilbert 